\title{
Epidermal growth factor receptor-mutant non-small cell lung Cancer and Choroidal metastases: long-term outcome and response to epidermal growth factor receptor tyrosine kinase inhibitors
}

Clémentine Bouchez ${ }^{1}$, Johan Pluvy', Ghassen Soussi', Marina Nguenang ${ }^{1}$, Solenn Brosseau', Morgan Tourne ${ }^{2}$, Mégane Collin ${ }^{3}$, Nathalie Théou-Anton ${ }^{2}$, Alice Guyard ${ }^{4}$, Jamila Ammar ${ }^{5}$, Antoine Khalil ${ }^{3}$, Gérard Zalcman ${ }^{1}$ and Valérie Gounant ${ }^{1 *}$

\begin{abstract}
Background: Choroidal metastases are the most common eye metastatic site. The prevalence of choroidal metastases in NSCLC patients has been reported to vary from 0.2 to $7 \%$ in historical series. Although previously reported, little is known about choroidal metastasis in Epidermal Growth Factor Receptor (EGFR)-mutant Non-small cell lung cancer (NSCLC). This study sought to describe the prevalence of choroidal metastases among patients with EGFR-mutated NSCLC and their characteristics, and to estimate their impact on prognosis.

Methods: We conducted a single-center retrospective study including all consecutive metastatic EGFR-mutant NSCLC patients, from Sept. 2015 to Oct. 2018. The EGFR-mutant NSCLC patients were identified via the Department of Genetics' files. Patients who exhibited choroidal metastases were compared to patients without choroidal metastases. Kaplan-Meier analysis and log-rank test were conducted to assess median overall survival (OS) from diagnosis for the two groups. The study was approved by the IRB as CEPRO number \#2020-010.

Results: Prevalence of choroidal metastases in EGFR-mutated NSCLCs was 8.4\% (7/83). Five were women, and four current or former smokers. Molecular analysis showed three tumors with exon 19 deletion, three with L858R mutation, and one with complex exon 21 mutation. The choroidal metastases were symptomatic in six/seven patients. Visual disturbances decreased in all but one symptomatic cases upon EGFR TKI, and the choroidal response was maintained over time.

Median follow-up was $42.2 \mathrm{mo}$ (95\%Cl [37.2-47.1]). Median OS in the choroidal metastasis group was 23.4 mo $(95 \% \mathrm{Cl}[0.1-51.4])$ versus $27.9 \mathrm{mo}(95 \% \mathrm{Cl}[16.9-38.9])$ in the non-choroidal metastasis group $(p=0.32)$. In the choroidal metastasis group, 2-year and 5-year OS were 47.6 and 0\%, respectively, versus 55.8 and $26.3 \%$ in the non(Continued on next page)
\end{abstract}

\footnotetext{
* Correspondence: valerie.gounant@aphp.fr

'Thoracic Oncology Department \& CIC1425-CLIP2 Early Phase Cancer Clinical

Trials Unit, University Hospital Bichat-Claude Bernard, Medical Faculty, Université de Paris, Hôpital Bichat, APHP, 46 Rue Henri Huchard, 75018 Paris, France

Full list of author information is available at the end of the article
}

C C The Author(s). 2020 Open Access This article is licensed under a Creative Commons Attribution 4.0 International License, which permits use, sharing, adaptation, distribution and reproduction in any medium or format, as long as you give appropriate credit to the original author(s) and the source, provide a link to the Creative Commons licence, and indicate if changes were made. The images or other third party material in this article are included in the article's Creative Commons licence, unless indicated otherwise in a credit line to the material. If material is not included in the article's Creative Commons licence and your intended use is not permitted by statutory regulation or exceeds the permitted use, you will need to obtain permission directly from the copyright holder. To view a copy of this licence, visit http://creativecommons.org/licenses/by/4.0/ The Creative Commons Public Domain Dedication waiver (http://creativecommons.org/publicdomain/zero/1.0/) applies to the data made available in this article, unless otherwise stated in a credit line to the data. 
(Continued from previous page)

choroidal metastasis subset.

Conclusions: Choroidal metastases in NSCLC EGFR-mutant patients are rare but should be systematically suspected in case of visual disturbance. TKls are efficient for treating visual symptoms. Whether choroidal metastases confer a worse prognosis remains unclear owing to the third-generation EGFR TKI osimertinib first-line registration.

Keywords: Lung cancer, NSCLC, EGFR mutation, Targeted therapy, Tyrosine kinase inhibitors, Choroidal metastases

\section{Background}

Choroidal metastases are the most common eye metastatic site, though the underlying mechanism is poorly understood. The choroid is the vascular, pigmented tissue lying between the sclera and the retina. Its principal role is to supply the retina and part of the optic nerve with oxygen and nutrients, thereby forming a vascular avenue to the sequestered tumor and a favorable environment for tumor growth [1].

In a retrospective study published in 1997 on 950 uveal metastases from 420 patients, the choroid was the most common ocular metastatic site (88\%), followed by the iris (9\%) and the ciliary body (2\%) [1]. Choroidal metastases from lung cancer (21\%) were mostly unilateral compared to those occurring in breast cancer (47\%) [1]. At diagnosis, the primary cancer was unknown in $34 \%$ of cases. Choroidal metastases can thus be inaugural [1].

Revealing symptoms include visual acuity loss, blurred vision, diplopia, and pain [2]. Mass effect and retinal signs, such as retinal detachment, retinal edema, and subretinal fluid, may also be observed.

Diagnosis necessitates ophthalmological expertise, owing to the many examinations required, such as autofluorescence, ultrasonography, optical coherence tomography, and fluorescein angiography [2].

Managing choroidal metastases has not been standardized and depends on the systemic disease and number and location of choroidal metastases. The spectrum of treatments extends from systemic therapies to local treatments, such as radiotherapy and intravitreal injection of anti-vascular endothelial growth factor [3, 4].

Non-small cell lung cancer (NSCLC) accounts for $80 \%$ of all lung cancer cases, with mutation of the epidermal growth factor receptor (EGFR) found in $10-15 \%$ in Caucasian patients [5].

Shimomura et al. first described the resolution of inaugural choroidal metastases, secondary to a lung cancer harboring an exon 19 deletion of the EGFR gene, in a woman treated with gefitinib [6].

To the best of our knowledge, the largest described series of choroidal metastases in lung cancer with an EGFR gene mutation comprised only two patients [7].

This study sought to describe the prevalence of choroidal metastases among patients with EGFR-mutated
NSCLC and their characteristics, and estimate their impact on prognosis.

\section{Methods \\ Patients}

We conducted a single-center retrospective study involving a cohort of consecutive metastatic NSCLC patients with EGFR mutations managed between September 2015 and October 2018 at Bichat University Hospital, Paris, France. The EGFR-mutant NSCLC patients were identified via the Department of Genetics' files, our institutional medical electronic file and drug prescription software. Patient demographics and clinical courses were retrospectively retrieved from medical records. These include: sex, age at diagnosis, history of tobacco smoking, choroidal metastasis status, EGFR mutation subtypes and co-mutation status.

All brain magnetic resonance imaging (MRIs) scans performed at diagnosis for EGFR-mutant patients were reviewed to identify asymptomatic choroidal metastases.

Death was considered the outcome of interest. The time origin was set to the date of the pathological diagnosis and the status of each patient (alive, deceased, or lost to follow) was determined on the study termination date (set to December 18, 2019).

According to the French regulation for observational retrospective studies, all patients received the printed institutional information sheet stating their pseudonymised personal clinical, biological and evolution data could be analyzed for medical and epidemiological studies, but that they keep the possibility to oppose to the utilization of such data. The computed patient study file was registered at the National Commission for Computing Liberties (CNIL registration number \#2,161,770), with the study approved by the Institutional Review Board of the French-Learned Society for Respiratory Medicine (Société de Pneumologie de Langue Française) (CEPRO number \#2020-010).

\section{Molecular analysis}

Molecular analyses were routinely performed for all non-squamous metastatic NSCLC cases at diagnosis. For liquid biopsy, blood samples were collected into Cell Free DNA collection tube ${ }^{\oplus}$ (Roche) to achieve $4 \mathrm{~mL}$ plasma. The Maxwell ${ }^{\circ} 16$ FFPE Plus LEV DNA Kit (Promega) and NucleoSnap ${ }^{\circ}$ DNA Plasma Kit 
(Macherey-Nagel) were used for DNA and cell-free DNA (cfDNA) extraction, respectively. The DNA and cfDNA quantity were assessed using the Qubit $^{\circ} 2.0$ Fluorometer (Qubit ${ }^{\circ}$ dsDNA BR Assay Kit) and Qubit ${ }^{\circ}$ DNA HS Assay Kit (Life Technologies-Thermo Fisher Scientific), respectively. The DNA was amplified using primers from Oncomine ${ }^{\mathrm{Tw}}$ Solid Tumor DNA and Oncomine Solid Tumor plus V2 (Life Technologies-Thermo Fisher Scientific). Usually, more than $200 \mathrm{ng}$ of cfDNA was obtained (median $0.9 \mathrm{ng} / \mu \mathrm{l}$ ). The minimum DNA concentration needed to perform the experiments has previously been defined by the manufacter is $20 \mathrm{ng}$ to assure a $0.1 \%$ sensitivity with next generation sequencing. The cfDNA was amplified using primers from Oncomine $^{\mathrm{Tm}}$ Lung cfDNA Assay (Life Technologies-Thermo Fisher Scientific). Sequencing was performed on S5XL System with the Ion 520 or 530 Chip (Ion Torrent, Thermo Fisher Scientific). The sequences were aligned with the hg19 human reference genome, with data analyzed by variant calling using the Torrent Suite software (Thermo Fisher Scientific) and Ion Reporter software for annotations of variants (Thermo Fisher Scientific). Potential mutations were retained on the DNA if their allelic frequency was $\geq 3 \%$ and coverage $>300 \mathrm{X}$, and on the cfDNA if their allelic frequency was $\geq 0.1 \%$ and mol count $>2$. Mutations were referred to the COSMIC database (GRCh37, COSMIC v84).

The EGFR mutations were classified according to exon location. When next-generation-sequencing (NGS) identified - at diagnosis, prior to EGFR tyrosine kinase inhibitor (TKI) therapy - one or more somatic mutations in other genes (TP53 mutation, KRAS mutation, BRAF mutation, PTEN mutation, DDR2 mutation, CTNNB1 mutation, or PIK3CA mutation) or multiple EGFR mutations, mostly combining an EGFR TKI-sensitizing mutation and uncommon mutation, these situations were defined as "co-mutation" or "complex EGFR mutation," respectively. Immunohistochemistry (IHC) was performed on initial diagnostic biopsy using anti-Rb clone 4H1 from Cell Signaling Technology (Danvers, MA) at 1:400 dilution, with normal stromal or inflammatory cells serving as internal positive control, in order to determine whether $\mathrm{Rb}$ protein expression was lost, likely indicating $R B$ gene mutation or deletion.

\section{Statistical analysis}

Categorical variables were expressed as frequencies and percentages. Student $\mathrm{T}$ test was used for independent samples to compare means, after checking the data follow a normal distribution (tested by Shapiro-Wilk method). Mann-Whitney $U$ test was used instead when the data was not normally distributed. Fisher's exact test was used to compare percentages. The median follow-up was evaluated using the reverse Kaplan-Meier estimator.
The impact of each variable on survival was studied in univariable analysis using the Kaplan-Meier method. The log-rank test was used to compare survival distributions between groups. At that step, hypothesis testing was two-tailed, and $p$-values were set at $<0.05$ for statistical significance. The hazard ratios (HR) and their respective $95 \%$ confidence intervals $(95 \% \mathrm{CI})$ were calculated from univariable analyses using Cox proportional hazards models. Multivariable Cox analysis was performed using backward stepwise regression. The tested variables in univariate overall survival (OS) analysis were age, sex, smoking status, choroidal metastasis status, EGFR mutation subtype, co-mutation status, complex EGFR mutations, and TP53 co-mutation. Only variables with a significance threshold $p \leq 0.20$ in univariate analysis were included as candidate variables in the modeling procedure. Choroidal metastasis status was forced into the multivariate model, whatever was its $p$-value in the univariate analysis. Statistical analyses were performed using IBM SPSS Statistics for Windows, version 25.0 (IBM Corp., Armonk, N.Y., USA).

\section{Results}

\section{Patient demographics and characteristics in the whole} study population (Table 1)

We identified 83 cases of metastatic NSCLC harboring an EGFR mutation (Table 1) in our electronic files during a three-year period. Of these, 20 cases were diagnosed earlier but referred to our Department for treatment during this time period. The other 63 were newly diagnosed NSCLC cases. Main clinical baseline characteristics are summarize in Table 1.

Among the 83 EGFR-mutant NSCLC patients, six exhibited choroidal metastases, revealed by visual disturbances. An additional case (Fig. 1) was identified upon a retrospective systematical analysis of all brain MRIs performed by an expert radiologist, resulting in a final number of 7 choroidal metastasis patients (8.4\%). This latter patient had no clinical visual disturbances.

\section{Tumor genetic profile in the whole study population (Table 1)}

Thirty-seven (44\%) tumors harbored exon 19 mutations (either $32(38 \%)$ deletions, and $5(6 \%)$ deletion-insertions). Overall, 33 (40\%) tumors had a mutation in EGFR exon 21, (31 [38\%] L858R, and two [2\%] L861Q). Four (5\%) tumors exhibited a missense mutation in exon 18 , and nine $(11 \%)$ a mutation in exon 20.

We found 11 tumors (13\%) with EGFR complex mutations associated with common or uncommon mutations, and two had two rare mutations associated together. Two tumors (2\%) presented with a T790M mutation in exon 20 of the EGFR gene at diagnosis, associated with a common activating mutation. Co-mutations involving 
Table 1 Baseline Characteristics of Patients with Non-Small-Cell Lung Cancer EGFR Mutation by Choroidal Metastasis Status

\begin{tabular}{|c|c|c|c|c|}
\hline Variables & All $n=83$ & $\begin{array}{l}\text { Choroidal } \\
\text { metastases } n=7\end{array}$ & $\begin{array}{l}\text { Non-choroidal } \\
\text { metastases } n=76\end{array}$ & $p$-value \\
\hline \multicolumn{5}{|l|}{ Age, years } \\
\hline Mean & 69 & 56 & 70 & \multirow[t]{2}{*}{$<10^{-6}$} \\
\hline Median (IQR) & $69(60-80)$ & $57(50-60)$ & $71(61-80)$ & \\
\hline \multicolumn{5}{|l|}{ Sex $(\%)$} \\
\hline Male & $37(45)$ & $2(29)$ & $35(46)$ & \multirow[t]{2}{*}{0.45} \\
\hline Female & $46(55)$ & $5(71)$ & $41(54)$ & \\
\hline \multicolumn{5}{|l|}{ Smoking status (\%) } \\
\hline Current smoker & $4(5)$ & $0(0)$ & $4(5)$ & \multirow[t]{3}{*}{0.79} \\
\hline Former smoker & $35(42)$ & $4(57)$ & $31(41)$ & \\
\hline Never smoker & $44(53)$ & $3(43)$ & $41(54)$ & \\
\hline \multicolumn{5}{|c|}{ Subtype of EGFR mutations (\%) } \\
\hline Exon 19 & $37(44)$ & $3(43)$ & $34(45)$ & \multirow[t]{3}{*}{1} \\
\hline Exon 21 & $33(40)$ & $3(43)$ & $30(39)$ & \\
\hline Others & $13(16)$ & $1(14)$ & $12(16)$ & \\
\hline \multicolumn{5}{|c|}{ Co-mutation status (\%) } \\
\hline Yes & $52(62)$ & $5(71)$ & $47(62)$ & \multirow[t]{3}{*}{1} \\
\hline No & $29(35)$ & $2(29)$ & $27(35)$ & \\
\hline Unknown & $2(2)$ & 0 & $2(3)$ & \\
\hline \multicolumn{5}{|c|}{ Complex EGFR mutations (\%) } \\
\hline Yes & $11(13)$ & $2(29)$ & $9(12)$ & \multirow[t]{3}{*}{0.36} \\
\hline No & $70(84)$ & $5(71)$ & $65(85)$ & \\
\hline Unknown & $2(2)$ & 0 & $2(3)$ & \\
\hline \multicolumn{5}{|c|}{ TP53 co-mutation (\%) } \\
\hline Yes & $40(48)$ & $4(57)$ & $36(47)$ & \multirow[t]{3}{*}{0.76} \\
\hline No & $41(50)$ & $3(43)$ & $38(50)$ & \\
\hline Unknown & $2(2)$ & 0 & $2(3)$ & \\
\hline
\end{tabular}

IQR interquartile range

EGFR epidermal growth factor receptor

the TP53 and EGFR genes were found in 40 tumors (48\%).

Furthermore, 4/83 (5\%) patients experienced SCLC transformation during disease evolution, involving 3/76 (4\%) patients without choroidal metastasis, and $1 / 7$ (14\%) with choroidal metastasis (Patient \#5). These four tumors harbored TP53 mutation at diagnosis.

\section{Clinical and molecular characteristics of Choroidal metastasis patients (Table 2 and Table 3)}

Seven patients (8.4\%) with choroidal metastases associated with EGFR-mutant NSCLC were retrieved in our retrospective cohort. Their clinical characteristics at diagnosis are shown in Table 2, while the choroidal metastasis features and their evolution are summarized in Table 3. Initial presentation of choroidal metastasis in Patient \#1 is shown in Fig. 2.

\section{Patient demographics and characteristics of Choroidal} metastasis patients

When comparing the clinical characteristics of the choroidal metastasis group with the remaining 76 patients, no statistically significant differences were found, except for a lower mean age in the choroidal metastasis group, $\left(p<10^{-6}\right)$. Most of the choroidal metastasis patients were women (five/seven cases, $71 \%$ ), and the majority (four of seven cases, 57\%) were current or former smokers, with two being active smokers. There was only one Asian patient, with three being of African origin.

In all patients (except Patient \#7, with retrospective MRI-based diagnosis), the choroidal metastases resulted in symptoms, such as pain, blurred vision, or visual acuity loss. The choroidal metastases were frequently unilateral (six of seven cases, 85\%). Brain MRI was performed at diagnosis in six out of seven patients, with choroidal 


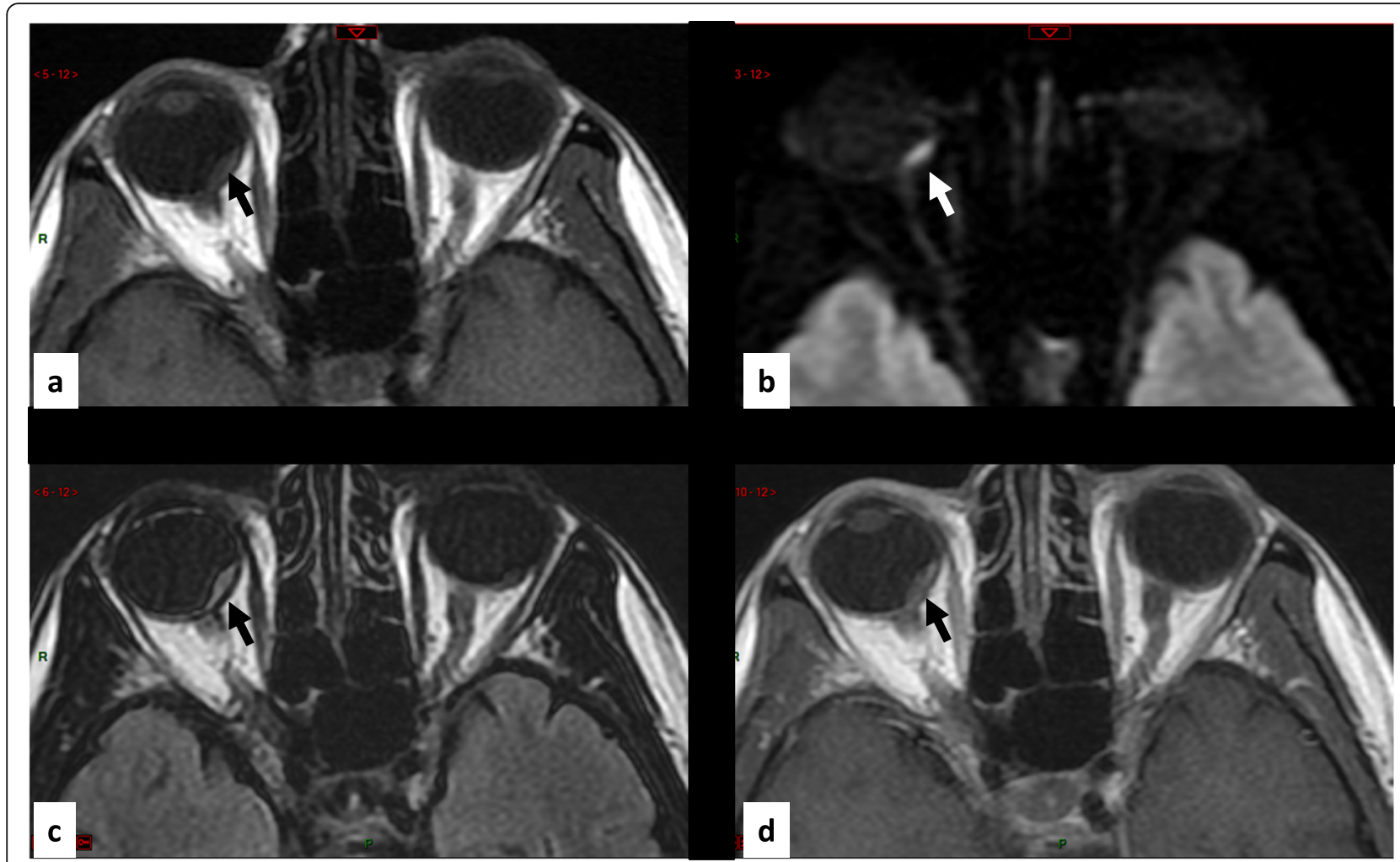

Fig. 1 MRI In axial plane focused on orbits with the following sequences in Patient \#7.) Spin-Echo T1-weighted image, it shows an oblong intraorbital lesion (arrow) in slight hypersignal within the orbit. b Diffusion-weighted image, it shows a frank hypersignal of the lesion (arrow). c FLAIR, it shows the lesion in slight hypersignal (arrow). d Spin-Echo T1-weighted image after contrast injection, it shows a slight enhancement of the intraorbital lesion (arrow)

metastases actually visible on MRI after a retrospective secondary analysis by an expert radiologist in five out of six patients, though all these lesions were missed on the first MRI report, except for those of Patient \#6.

The choroid metastases were associated with other metastatic sites like brain metastases in five out of seven patients without any obvious leptomeningeal carcinomatosis on brain MRI. Four out off five evaluable patients who were treated with TKI showed an objective response with visual symptom improvement. Local response was maintained in all cases, and no choroidal local progression occurred, even in case of tumor progression at other metastatic sites. Four out of seven patients received osimertinib as second-line therapy based on the emergence of T790M resistance mutation. All patients received a pemetrexed/platinum-based chemotherapy doublet during the course of the disease. All lines of treatments are available in Supplementary Data 1. One patient out of seven also underwent radiotherapy of the choroidal metastasis.

\section{Genetic profile of EGFR-mutated NSCLC of Choroidal metastasis patients}

The molecular tumor status of the choroidal metastasis patients was consistent with that of the remaining population, as $85 \%$ had a common activating EGFR mutation (Table 1). One patient had a rare, complex exon 21 mutation diagnosed late in the NSCLC course, using whole exome sequencing.

One patient displayed a T790M mutation in the EGFR gene exon 20 at diagnosis at the same allele frequency as the common exon 21 mutation (Patient \#4, L858R mutation). The tumor molecular patterns of the seven patients with choroidal metastases are shown in Table 2: four patients had TP53 mutations, four had lost Rb immunohistochemical expression, indicative of a $\mathrm{Rb}$ probable gene deletion, and three had simultaneously both events at diagnosis supporting the preexistence of a subclone with small-cell carcinoma features. However, during the study period of time, only one case of SCLC histological transformation was observed in one out of seven patients (Patient \#5), who similarly exhibited TP53 mutation and $\mathrm{Rb}$ loss expression in the diagnostic sample.

\section{Overall survival analysis (Fig. 3)}

Median follow-up time in the whole study population was 42.2 mo., 95\%CI [37.2-47.1]. On the study termination 





Bouchez et al. BMC Cancer $\quad$ (2020) 20:1186

Page 7 of 12

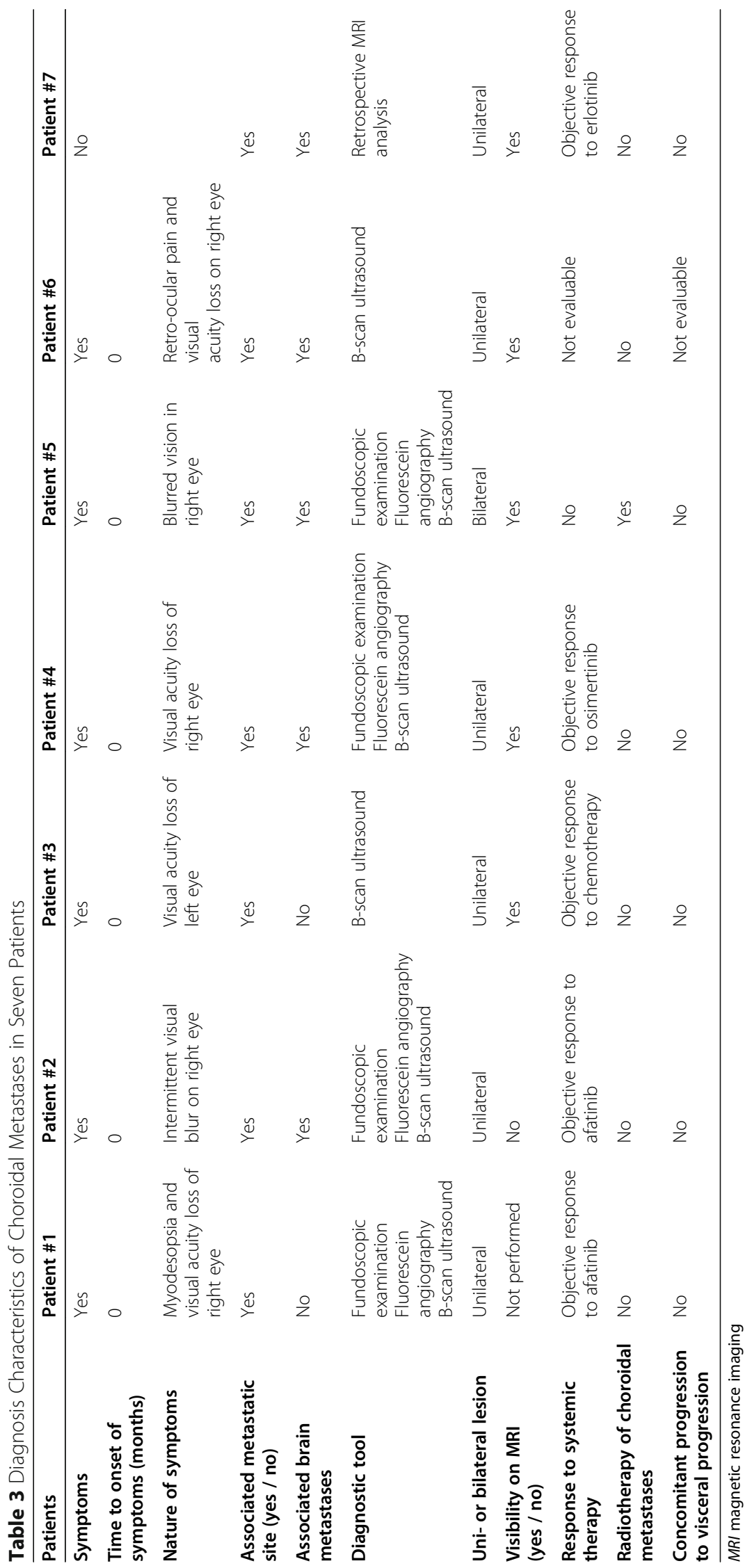



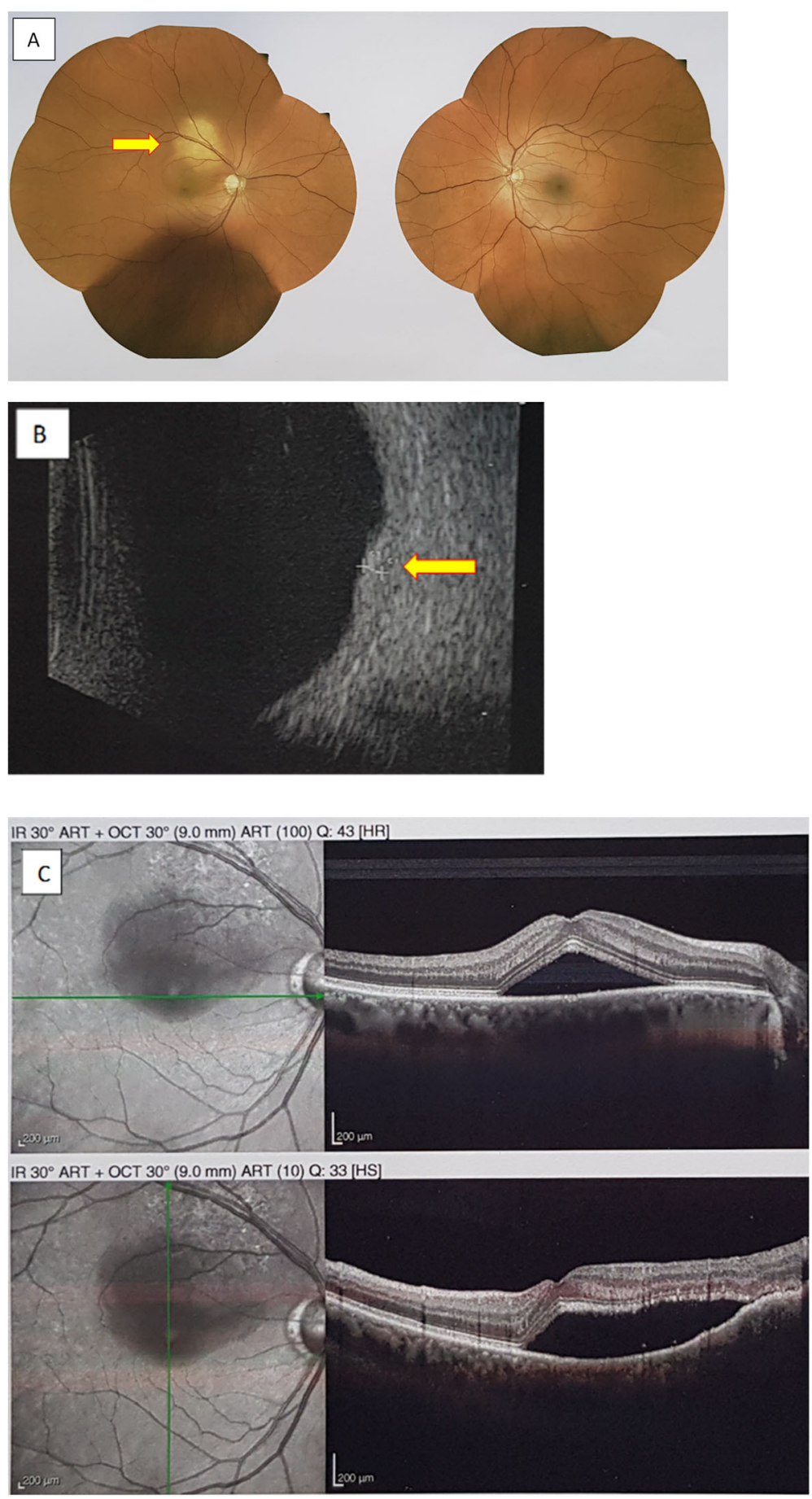

Fig. 2 Initial presentation of right choroidal metastasis in Patient \#1. a Fundus examination showing well-defined yellowish-colored circular submacular lesion on the right eye (arrow). b B-scan echography showing a right dome-shaped lesion on macula with hyperreflectivity and a maximal elevation of $1,12 \mathrm{~mm}$ (arrow). c Fluorescein angiography showing retinal detachment with the presence of subretinal fluid on the right eye 


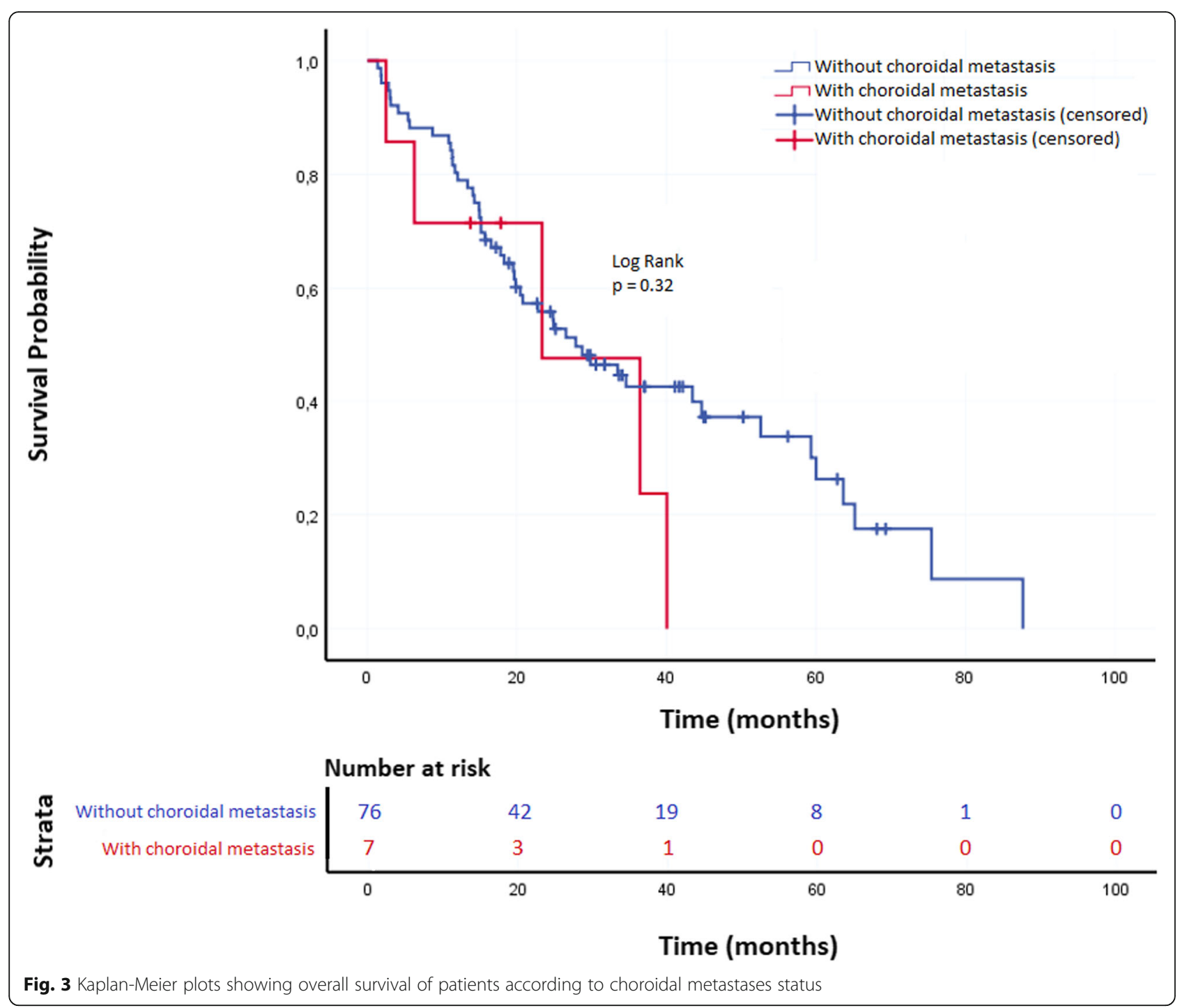

date, 28 patients (33.7\%) were still alive and 55 patients (66.3\%) were deceased. No patients were lost to follow-up.

Median OS in the whole study population was 27.9 mo. (95\% CI [17.1-38.6]) with 55.3 and 24.1\%, 2-year and 5-year OS, respectively.

In univariable analysis, median OS in the choroidal metastasis group was $23.4 \mathrm{mo} .95 \% \mathrm{CI}$ [0.1-51.4]) versus 27.9 mo. 95\%CI [16.9-38.9] in the non-choroidal metastasis group $(p=0.32)$ (Fig. 3). In the choroidal metastasis group, 2-year and 5-year OS were 47.6 and $0 \%$, respectively. In the non-choroidal metastasis group, 2-year and 5 -year OS were found to be 55.8 and $26.3 \%$, respectively. The presence of EGFR exon 19 deletion was the only variable significantly associated with a longer median OS (52.6 mo., 95\%CI [24.1-81.1]) as compared with patients showing EGFR exon 21 point mutation (26.6 mo., 95\%CI [15.3-37.9]) or non-conventional EGFR mutations (19.8 mo., 95\%CI [15.3-24.4]), $p=0.03$.
After adjusting for variables showing a $p$-value $\leq 0.02$ in the univariate analysis, i.e. EGFR mutation subtype, and TP53 mutations, choroidal metastasis did not show any impact on survival (Supplementary data 2) while EGFR mutation subtype remained as an independent prognostic factor, since patients with exon 21 and uncommon EGFR mutations had significantly shorter survivals, with adj. $\mathrm{HR}=1.89,95 \% \mathrm{CI}[1.01-3.55](p<0.05)$, and $2.4295 \% \mathrm{CI}$ [1.11-5.31] $(\mathrm{p}=0.03)$, respectively, as compared with patients whose tumor harbored EGFR exon 19 deletion.

\section{Discussion}

The specific prevalence of choroidal metastases in EGFR-mutant NSCLC patients is still unknown. Herein, we report the characteristics of seven patients with choroidal metastasis from a cohort of 83 consecutive EGFRmutant NSCLC patients (8.4\%). Based on published data, 
the prevalence of choroidal metastases in NSCLC patients has been reported to vary from $0.2 \%[1,8]$ to $7 \%$ [9] in historical series, reaching $10 \%$ in post-mortem histopathological studies [10]. We take charge of nearly 300 new metastatic lung cancer patients each year in our department, pertaining to a 945-bed tertiary University Hospital in the North of Paris, covering a population of roughly 4.0 million inhabitants. Thus, 900 Stage IV lung cancer patients were treated during the same time period. Using the key terms "choroidal metastasis" in our database, we have identified 10 cases of lung cancer with choroidal metastasis over this period: 7 adenocarcinoma harboring EGFR mutations (subject of this study), 1 case with BRAF V600E mutation and 2 cases $\mathrm{K}$-Ras mutated (including one case associated with STK11 mutation).

Among the seven patients with choroidal metastases in EGFR-mutant NSCLC, six were symptomatic, which was concordant with Shields' cohort of 420 patients with various primary cancers over a 20-year period [1], of whom most were symptomatic. The choroidal metastases were inaugural in these six symptomatic cases, while being a revealing symptom in the first patient described.

Our seven-patient series only differed in age from the non-choroidal metastases population, showing a younger mean age. Most choroidal metastases concerned women, which is not unexpected taking account for the larger female prevalence in patients with EFGR-mutant tumor. However, if lung cancer is the most common source of choroidal metastases in males (40\%), it is the second most common etiology in females, after breast cancer (68\%) [1].

Concomitant TP53 mutation and Rb expression loss were unlikely to be predictors of choroidal metastasis, although it has been previously associated to SCLC histological transformation, since only three out of seven patients showed TP53/Rb double alterations with only a single patient exhibiting SCLC transformation upon EGFR TKI in our series.

In the United States, the frequency of EGFR testing was reported to be only $22 \%$ for Stage IV lung adenocarcinoma in the whole country in 2010 [5], though the guidelines recommend systematic testing for all Stage IV lung adenocarcinomas [11]. Although the rate of EGFR testing may have improved meanwhile, the occurrence of choroidal metastases should strongly support EGFR testing, considering EGFR TKI efficacy.

Our patients had at least one more metastatic site, which is consistent with Kreusel et al.'s series, in which the only risk factor of developing choroidal metastases in univariate analysis was the presence of at least two other metastatic sites [9].

In our series, a systematic control ophthalmological examination upon EGFR-TKI treatment was not performed and we could not correlate symptom decrease and choroidal lesion disappearance on dilated fundus ophthalmoscopy. Conversely, sub-retinal detachment, on echography or fluorescein angiography, frequently disappeared.

A retrospective analysis of brain MRI by an expert radiologist, who was blinded to the choroidal metastasis diagnosis, identified choroidal metastases in five patients, with a previously known diagnosis in four, and a previously unknown in the remaining one. The choroidal metastases' appearance upon MRI consisted of a welldemarcated mass iso-intense on T1-weighted images and hypointense on T2-weighted images [12]. Indeed, MRI has proven useful in differentiating choroidal metastases from primary uveal neoplasm, especially when ophthalmological visualization is obscured by subretinal effusion [13, 14]. Since brain imaging is essential to the diagnostic assessment of Stage IV NSCLC, a specific examination focused on the eyes should be recommended, particularly when EGFR-mutant lung cancer patients experience visual symptoms, such as visual disturbance.

Among four out of five evaluable patients treated by EFGR TKI, this treatment yielded a dramatic response with diminution and even disappearance of visual troubles after a 1-month course. Conversely, one patient experienced regression of visual troubles upon chemotherapy prior to TKI initiation. Tumor progression secondary to TKI resistance was not associated with choroidal progression, and choroidal response to TKIs appeared to be maintained, even in case of extrachoroidal progression.

The first described choroidal metastasis cases in possibly EGFR-mutant Asian patients (not molecularly assessed), published in 2009-2010, revealed the efficacy of EGFR TKI (in association with intravitreal bevacizumab) $[15,16]$. Since then, a few case reports have confirmed the ability of first- or second-generation TKIs to induce choroidal metastasis regression in patients with tumor EGFR mutation [7, 17, 18]. The efficacy of third-generation EGFR TKI osimertinib on choroidal metastasis was reported once in an NSCLC patient with T790M EGFR tumor mutation [19]. Our series consisted of patients treated before first-line setting registration of osimertinib, though four out of seven received osimertinib as post-front-line treatment. Owing to osimertinib efficacy on brain metastases demonstrated in large Phase 3 trials in patients with or without T790M mutation [20, 21], osimertinib should also be considered the first-line treatment of choice in EGFR-mutant lung cancer patients with choroidal metastases.

The specific prognosis of EGFR-mutated lung cancer with choroidal metastases is unknown. In a study by Shah [22] involving 194 lung cancers (NSCLC and 
5. Enewold L, Thomas A. Real-world patterns of EGFR testing and treatment with Erlotinib for non-small cell lung Cancer in the United States. PLoS One. 2016;11:e0156728.

6. Shimomura I, Tada Y, Miura G, et al. Choroidal metastasis of non-small cell lung cancer that responded to gefitinib. Case Rep Ophthalmol Med 2013; 2013:213124.

7. Riess JW, Nagpal S, Das M, Neal JW, Kim JW, Wakelee HA. A case series of NSCLC patients with different molecular characteristics and choroidal metastases: improvement in vision with treatment including pemetrexed and bevacizumab. J Thorac Oncol. 2013;8:e17-8.

8. Su HT, Chen YM, Perng RP. Symptomatic ocular metastases in lung cancer. Respirology. 2008;13:303-5.

9. Kreusel KM, Wiegel T, Stange M, Bornfeld N, Hinkelbein W, Foerster MH. Choroidal metastasis in disseminated lung cancer: frequency and risk factors. Am J Ophthalmol. 2002:134:445-7.

10. Nelson CC, Hertzberg BS, Klintworth GK. A histopathologic study of 716 unselected eyes in patients with cancer at the time of death. Am J Ophthalmol. 1983;95:788-93.

11. Lindeman $\mathrm{NI}$, Cagle PT, Aisner DL, et al. Updated molecular testing guideline for the selection of lung Cancer patients for treatment with targeted tyrosine kinase inhibitors: guideline from the College of American Pathologists, the International Association for the Study of Lung Cancer, and the Association for Molecular Pathology. Arch Pathol Lab Med. 2018; 142:321-46.

12. Arepalli S, Kaliki S, Shields CL. Choroidal metastases: origin, features, and therapy. Indian J Ophthalmol. 2015;63:122-7.

13. Mafee MF, Peyman GA, Peace JH, Cohen SB, Mitchell MW. Magnetic resonance imaging in the evaluation and differentiation of uveal melanoma. Ophthalmology. 1987;94:341-8.

14. Chong JT, Mick A. Choroidal metastasis: case reports and review of the literature. Optometry. 2005;76:293-301.

15. Kim SW, Kim MJ, Huh K, Oh J. Complete regression of choroidal metastasis secondary to non-small-cell lung cancer with intravitreal bevacizumab and oral erlotinib combination therapy. Ophthalmologica. 2009;223:411-3.

16. Inoue M, Watanabe $Y$, Yamane $\mathrm{S}$, et al. Choroidal metastasis with adenocarcinoma of the lung treated with gefitinib. Eur J Ophthalmol. 2010; 20:963-5.

17. Contreras-Díaz M, Medina-Tapia A, Martínez-Bernal G, et al. Choroidal metastasis as a presenting manifestation of a lung adenocarcinoma with response to afatinib. Arch Soc Esp Oftalmol. 2016;91:551-5.

18. Nair AG, Asnani HT, Mehta VC, et al. Tyrosine kinase inhibitors in the treatment of Choroidal metastases from non-small-cell lung Cancer: a case report and review of literature. Ocul Oncol Pathol. 2017;3:28-33.

19. Mariachiara M, Celeste R, Federico F, Nicole B, Antonio C. Choroidal metastasis from non-small-cell lung cancer responsive to Osimertinib: a case report: efficacy of a third-generation epidermal growth factor tyrosine kinase inhibitor. Int Ophthalmol. 2018;38:2669-75.

20. Mok TS, Wu Y-L, Ahn M-J, et al. Osimertinib or platinum-Pemetrexed in EGFR T790M-positive lung Cancer. N Engl J Med. 2017;376:629-40.

21. Soria JC, Ohe Y, Vansteenkiste J, et al. Osimertinib in untreated EGFR-mutated advanced non-small-cell lung Cancer. N Engl J Med. 2018;378:113-25.

22. Shah SU, Mashayekhi A, Shields CL, et al. Uveal metastasis from lung cancer: clinical features, treatment, and outcome in 194 patients. Ophthalmology. 2014;121:352-7.

\section{Publisher's Note}

Springer Nature remains neutral with regard to jurisdictional claims in published maps and institutional affiliations.

Ready to submit your research? Choose BMC and benefit from:
- fast, convenient online submission
- thorough peer review by experienced researchers in your field
- rapid publication on acceptance
- support for research data, including large and complex data types
- gold Open Access which fosters wider collaboration and increased citations
- maximum visibility for your research: over 100M website views per year
At BMC, research is always in progress.
Learn more biomedcentral.com/submissions

